\title{
A STUDY OF THE STATIONARY BED OF SUPPORTED LIQUID PHASE CATALYSTS
}

\author{
Hiroshi KOMIYAMA* AND HakUai INOUE \\ Department of Chemical Engineering, University of Tokyo, \\ Tokyo, 113
}

\begin{abstract}
The catalytic behavior of a porous particle containing a liquid-phase catalyst in its pores is investigated by the catalytic oxidation of ethylene (the Wacker-Höchst process). The activity of the catalyst is proved to be dependent upon the properties of the carrier materials, their sizes and the operating conditions. The experimental results are analyzed on the basis of measurement of the intrinsic kinetics and the effective diffusivity in the liquid-filled pores, and from these results the effectiveness factors of the catalysts are derived. A new technique to create a highly-dispersed state of catalyst solution inside the carrier materials and to eliminate the diffusion resistances is successfully established.
\end{abstract}

\section{Introduction}

The discovery of various liquid-phase catalysts, frequently containing transition metal complexes, stimulated the recent development of industrial processes. A successful example is the conversion of olefin to aldehyde by the use of palladium complex, famous as the Wacker-Höchst process. Advances in the field of metal complex catalysts will produce an increasing number of useful reactions in the future. However, the present industrial equipment for such homogeneous reactions in the liquid phase, usually a gas-bubbling type reactor, involves mechanical and reaction engineering problems. The former include the corrosion of the walls of the equipment, catalyst loss by entrainment and so on. Of the latter, backmixing in the reactor and difficulty in predicting and controlling its performance are serious.

The holding system of liquid-phase catalysts as shown in this paper, that is, a stationary bed of porous particles containing a liquid-phase catalyst in their pores, will eliminate the disadvantages otherwise encountered. However, a new problem will arise for the system. That is, the use of ordinary-size porous material may result in low activity or low selectivity owing to significant mass transfer resistances. This is one of the main reasons why the system has not been developed extensively in industry, despite the fact that its use was advocated as early as $1939^{9,10)}$. The information on the solid catalyst obtained in the previous papers of the authors ${ }^{6,7)}$ offers a new approach to the solution of this problem. The high

Received December 17, 1974.

Presented at the 36th Annual Meeting of The Soc. of Chem.

Engrs., Japan, at Tokyo, 1971. activity of the commercial nickel catalyst employed in those studies has been proved to be caused by the dispersion of the active parts in the form of microparticles within the catalyst pellet and rapid diffusion through its macropore. Provided that a liquid catalyst within a porous material is dispersed as finely as the dispersion, rapid diffusion through the empty pores may eliminate significant intraparticle resistances and yield high activity.

The supported liquid-phase catalyst was first proposed by Moravec et al. ${ }^{9,10)}$; the recent studies of Rony ${ }^{11,12)}$ and Acres et al. ${ }^{1)}$ made some theoretical and experimental contributions in this fields. These studies paid little attention to the problem stated above and the effects of system parameters on the behavior of the catalyst have never been elucidated. Furthermore, application of the system has been restricted to essentially nonvolatile liquid-phase catalysts.

The main purpose of this work is:

1) to examine the stability of the activity of the catalyst,

2) to study kinetically the supported liquidphase catalyst in comparison with a bubble column reactor,

3) to apply the theory of the effectiveness factor to the catalyst system, and

4) to create a highly dispersed state of the liquidphase catalyst within a porous material.

The reaction chosen for these studies was the conversion of ethylene to acetaldehyde catalyzed by a hydrochloric acid solution of $\mathrm{PdCl}_{2}$ and $\mathrm{CuCl}_{2}$ (the Wacker-Höchst process). Since the pioneering work was undertaken by Schmidt et al. ${ }^{13)}$, considerable effort has been devoted to clarifying the mechan- 
ism of this reaction and the parameters affecting its rate $^{14)}$. The reaction system involves the conversion of ethylene to acetaldehyde accompanied by the reduction of palladium ion, the oxidation of the resulting metallic palladium by cupric chloride and the reoxidation of cuprous chloride with oxygen. The palladium ion functions as a catalyst, and the rate of the overall reaction is expressed as Eq. (5) ${ }^{14)}$.

$$
\begin{aligned}
\mathrm{C}_{2} \mathrm{H}_{4}+\mathrm{PdCl}_{2}+\mathrm{H}_{2} \mathrm{O} & \longrightarrow \mathrm{C}_{2} \mathrm{H}_{4} \mathrm{O}+2 \mathrm{HCl}+\mathrm{Pd} \\
\mathrm{Pd}+2 \mathrm{CuCl}_{2} & \longrightarrow \mathrm{PdCl}_{2}+2 \mathrm{CuCl} \\
2 \mathrm{CuCl}+(1 / 2) \mathrm{O}_{2}+2 \mathrm{HCl} \longrightarrow & \longrightarrow \mathrm{CuCl}_{2}+\mathrm{H}_{2} \mathrm{O}
\end{aligned}
$$

$$
\begin{aligned}
\mathrm{C}_{2} \mathrm{H}_{4}+(1 / 2) \mathrm{O}_{2} & \stackrel{\mathrm{PdCl}_{2}, \mathrm{CuCl}_{2}}{\longrightarrow} \mathrm{C}_{2} \mathrm{H}_{4} \mathrm{O} \\
r & =\frac{k\left[\mathrm{PdCl}_{2}\right]}{\left[\mathrm{Cl}^{-}\right]^{2}\left[\mathrm{H}^{+}\right]}\left[\mathrm{C}_{2} \mathrm{H}_{4}\right]
\end{aligned}
$$

\section{Fixed-Bed Reactor of Supported Liquid-Phase Catalyst}

\section{Preparation of the supported liquid-phase catalyst}

The catalyst solution was usually of the same composition $\left(\mathrm{PdCl}_{2} 5.64 \mathrm{mmol} / l, \mathrm{CuCl}_{2} 0.1 \mathrm{~mol} / l, \mathrm{HCl}\right.$ $0.06 \mathrm{~mol} / \mathrm{l}$ ), which was in the range where the deposition of metallic palladium could not be observed. A porous glass supplied by the Tokyo Shibaura Electric Co. Ltd., whose pore diameter is smaller than $50 \AA$, and a porous alumina named FCC of average pore diameter about $10 \mu$, supplied by the Fujimi Kenmazai Kogyo Co. Ltd., were employed as carrier materials of the catalyst solution. The use of chemically inactive materials is important for the system. Some of the other porous materials, such as molecular sieves and active alumina, significantly affected the catalyst activity.

Owing to the high ionization potential, a palladium ion easily loses its charge when in contact with other metals, and so carrier materials must be cleaned from impurities. They were treated with a hydrochloric acid solution and then with pure boiling water. Finally they were heated and dried in a vacuum. Then, the addition of the catalyst solution to the evacuated porous materials filled the pores with the solution. The prepared catalyst pellet was proved to contain $0.25 \mathrm{~g}$ of catalyst solution per $1.0 \mathrm{~g}$ of carrier material, by decrease in weight when dried and by means of colorimetric determination of palladium ion in the solution in which a definite amount of the catalyst pellets was soaked. This amount of the catalyst solution shows that the whole pore volume is filled with it.

\section{Equipment and measurement procedure}

The apparatus employed in the experiments is shown schematically in Fig. 1. A reactor of a glass tube (I.D. $10 \mathrm{~mm}$ ) and a pre-saturator, which is a small bubble column contactor filled with a hydrochloric acid solution of the same concentration as the

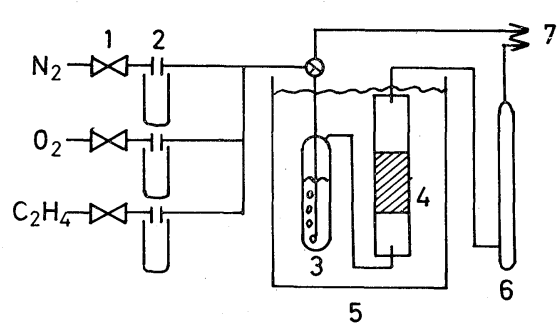

1. valve

3. pre-saturator

2. flow meter

5. thermostated vessel

4. reactor

7. gas fractometer

Fig. 1 Schematic diagram of apparatus

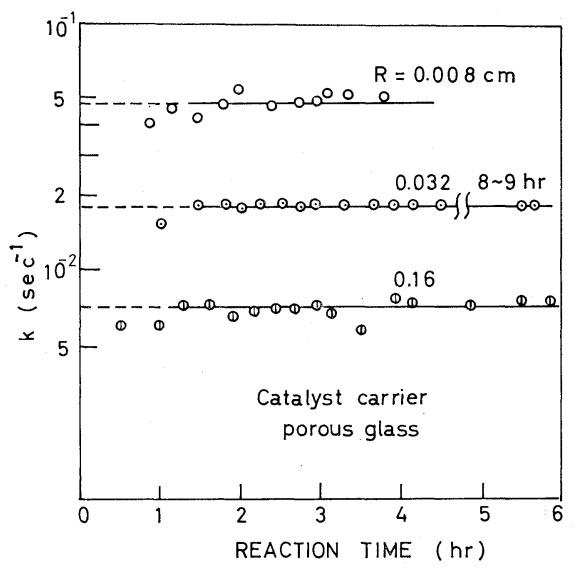

Fig. 2 Catalytic activity change with time

catalyst solution, were placed in a thermostated vessel. The use of the pre-saturator prevented vaporization of the solvent of the catalyst solution. A distillatory column was connected to the outlet of the reactor to remove water vapor from the effluent gas and to perform a reliable determination of gas composition by means of gas chromatography.

The standard experimental conditions are as follows:

reaction temperature: $70^{\circ} \mathrm{C}$

superficial gas velocity: $0.034 \mathrm{~cm} / \mathrm{sec}$

feed gas composition: $\mathrm{N}_{2}=61 \%, \mathrm{O}_{2}=37 \%$,

$$
\mathrm{C}_{2} \mathrm{H}_{4}=2.3 \% \text {. }
$$

\section{Results}

1) Stability of catalyst activity Experimental measurements made over a period of ten hours showed that the activity of the supported liquidphase catalysts was very stable (Fig. 2). The rate constant was calculated assuming a first-order rate form proportional to the concentration of ethylene in the catalyst solution.

$$
\begin{gathered}
k=\frac{-K \ln (1-X)}{W / F} \\
F=F^{\circ} \frac{760}{760-\mathrm{P}_{\mathrm{H}_{2} \mathrm{O}}, T_{\text {reactor }}} \frac{T_{\text {reactor }}}{T_{\text {room }}} \\
K=C_{\mathrm{C}_{2} \mathrm{H}_{4}, \text { gas }} / C_{\mathrm{C}_{2} \mathrm{H}_{4}, \text { iqui id }}
\end{gathered}
$$




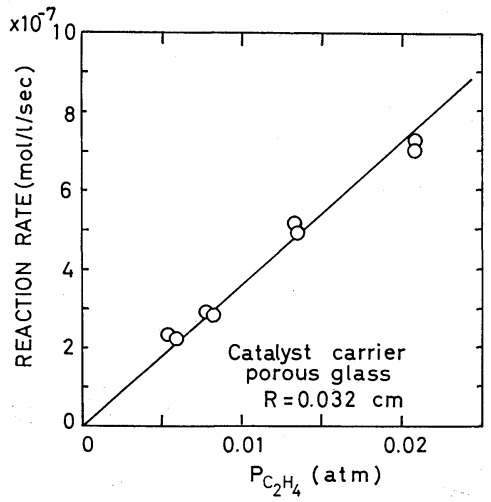

Fig. 3 Reaction rate vs. partial pressure of ethylene

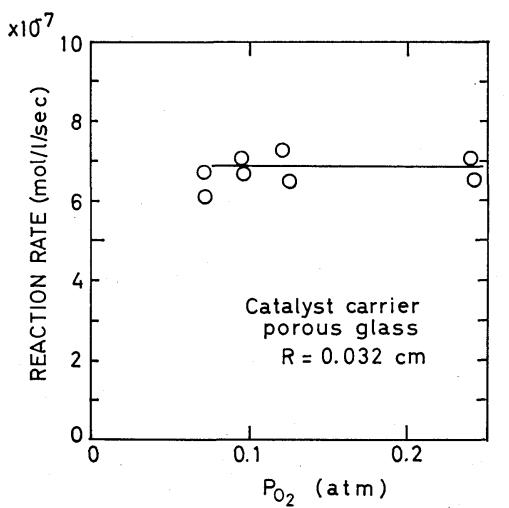

Fig. 4 Reaction rate vs. partial pressure of oxygen

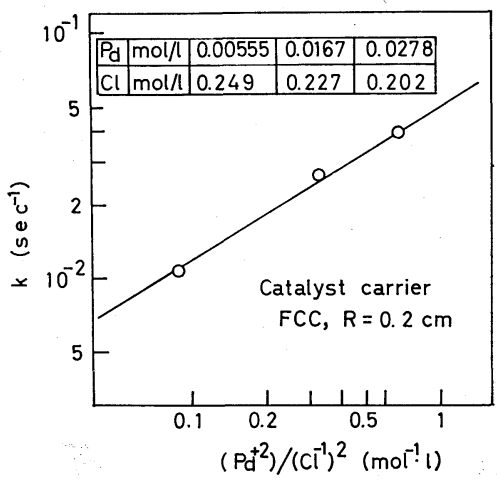

Fig. $5 k$ vs. catalyst composition

$K$ and $W$ represent respectively the gas-liquid partition coefficient of ethylene and the total volume of the catalyst solution contained in the catalyst pellets in the reactor. $\quad F^{\circ}$ and $F$ are respectively the volumetric flow rates at the inlet of the pre-saturator and in the reactor.

2) Kinetic studies Figs. 3 and 4 show that $r \propto$ $P_{\mathrm{C}_{2} \mathrm{H}_{4}} P_{\mathrm{O}_{2}}^{0}$, in accord with the results derived from the measurements by the bubble column reactor shown later and by many other investigators ${ }^{14)}$. Fig. 5 shows that $k \propto\left[\mathrm{Pd}^{2+}\right]^{0.57}$. Fig. 6 shows the dependency of $k$ on temperature. The indicated activation energy for $k$ is $9.6 \mathrm{kcal} / \mathrm{mol}$. Here, the change of $K$ with temperature was taken into account.

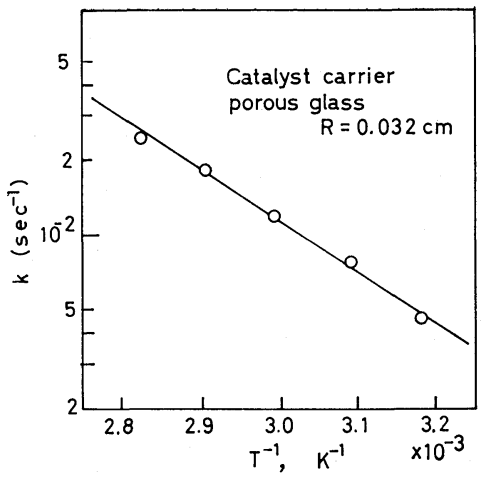

Fig. 6 Reaction rate constant vs. reciprocal of temperature

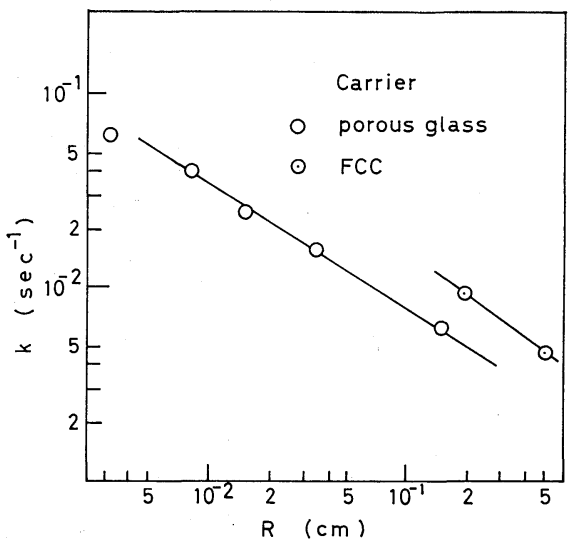

Fig. 7 Effect of catalyst size

3) Effects of pellet size and carrier material on catalyst activity Reaction rate measurements were made using two kinds of the porous materials mentioned before as the carriers, with sizes from $30 \mu$ to $5 \mathrm{~mm}$. As shown in Fig. 7, catalytic activity was strongly related to the kind and size of carrier materials.

These results will be discussed in the latter part of this paper, based upon the information on the intrinsic kinetics of this homogeneous reaction and the effective diffusivity of the liquid-filled porous materials.

\section{Bubble Column Reactor}

Data were taken to examine the intrinsic kinetics of the reaction using the same equipment as in the above studies, except that the fixed-bed reactor was replaced by a glass tube (I.D. $10 \mathrm{~mm}$ ) equipped with a gas inlet tube having a fritted glass ball (D. $6 \mathrm{~mm}$ ) at its end, through which the reacting gas mixture was bubbled into the catalyst solution.

As shown in Fig. 8, at a constant palladium ion concentration, the measured reaction rate constant increased with the increase of the total flow rate and finally converged to a certain maximum. This fact indicates that the rate-determining step shifts from gas-to-liquid mass transfer to homogeneous reaction, 


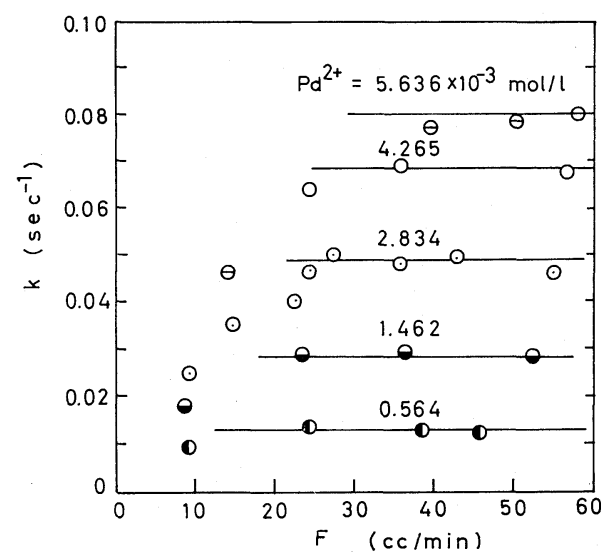

Fig. 8 Effect of flow rate on the measured reaction rate constant

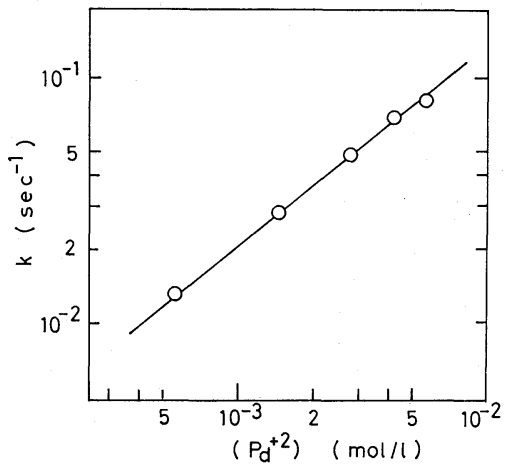

Fig. 9 Reaction rate constant vs. palladium ion concentration

as the total flow rate increases. For example, the overall rate is controlled by homogeneous reaction when the total flow rate is more than $40 \mathrm{ml} / \mathrm{min}$. Under this condition, bubbles were smaller than $1 \mathrm{~mm}$ and gas holdup in the reactor was more than $30 \%$.

The kinetic studies were carried out in the reaction controlling range.

Figs. 9 and 10 respectively show that $k \propto\left[\mathrm{Pd}^{2+}\right]^{0.83}$ and $r \propto \mathrm{P}_{\mathrm{C}_{2} \mathrm{H}_{4}}$. The true activation energy for the reaction was proved to be $14.7 \mathrm{kcal} / \mathrm{mol}$ from Fig. 11, where the reaction rate constants were expressed by $k^{\circ}\left(=k\left(\left[\mathrm{Cl}^{-}\right]^{2}\left[\mathrm{H}^{+}\right] /\left[\mathrm{Pd}^{2+}\right]\right)\right)$ instead of $k$, eliminating the effects of the composition of the catalyst solution. The values of $k^{\circ}$ from previous work are plotted by small circles and the straight lines are drawn to represent the activation energy.

\section{Effective Diffusion Coefficient in the Liquid Phase Supported in Porous Materials}

$\mathrm{KCl}$ solution of $1.0 \mathrm{~mol} / \mathrm{l}$ was supported by carrier materials in much the same manner as the catalyst pellets were prepared. The resultant pellets were soaked in pure water being agitated by a magnetic stirrer and controlled within $0.5^{\circ} \mathrm{C}$. The diffusion rate of $\mathrm{KCl}$ from the pellets into the water was meas-

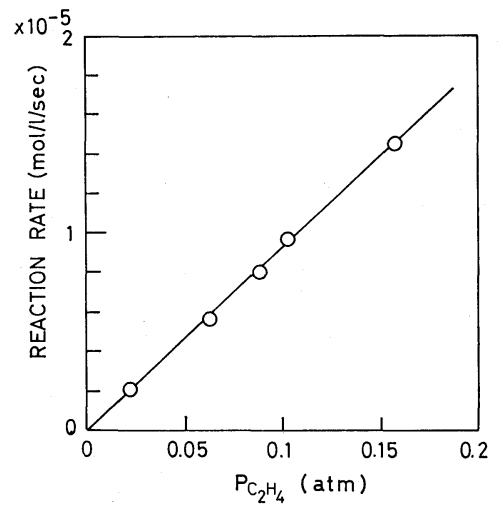

Fig. 10 Reaction rate vs. partial pressure of ethylene

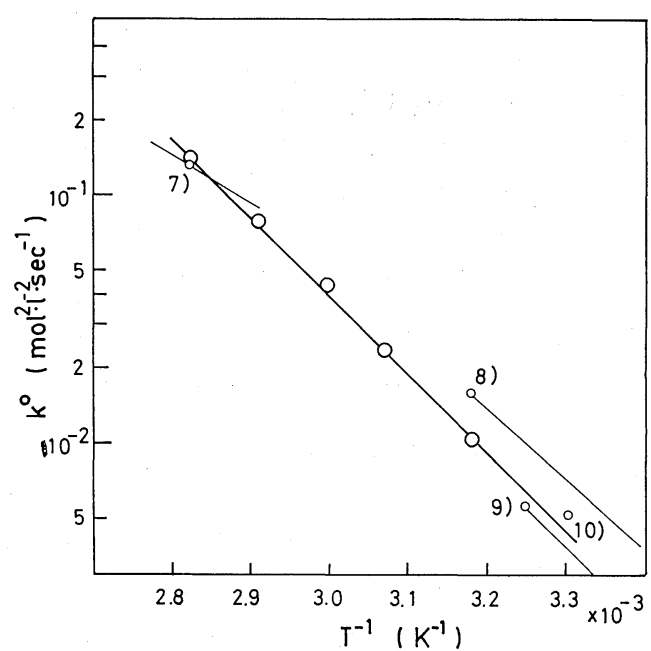

(Numbers on the small circles represent the references.)

Fig. 11 Arrhenius plot for $k^{\circ}$

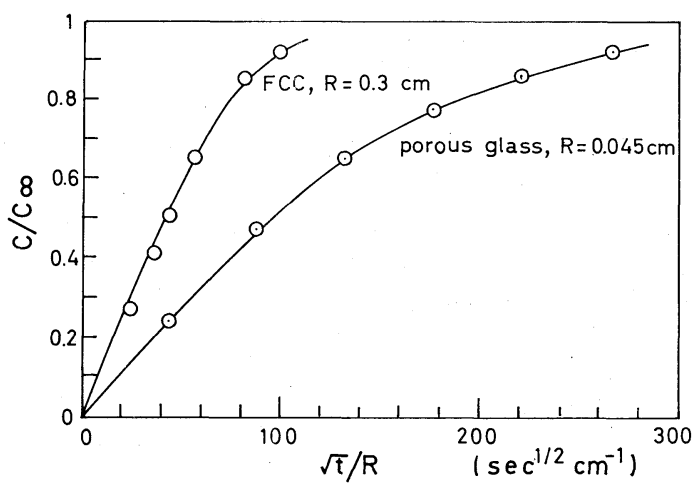

Fig. 12 Desorption rate of $\mathrm{KCl}$ from porous material $\left(25^{\circ} \mathrm{C}\right)$

ured by the electric conductivity of the water. The effective diffusion coefficient was estimated by comparison of the measured diffusion rate with the theoretical one ${ }^{2)}$. Some examples of the desorption curves are shown in Fig. 12. It should be noted that the effective diffusion coefficient is defined as $D / \tau$, instead of $\theta D / \tau$ as usually defined in a gas-solid system. The tortuosity factor was 7.0 for the porous glass and 1.3 for the porous alumina. These tortuo- 


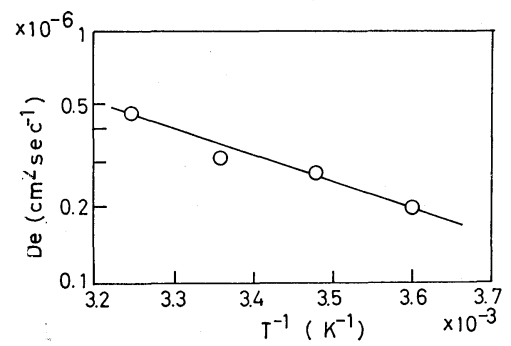

Fig. 13 Arrhenius plot for effective diffusivity (porous glass)

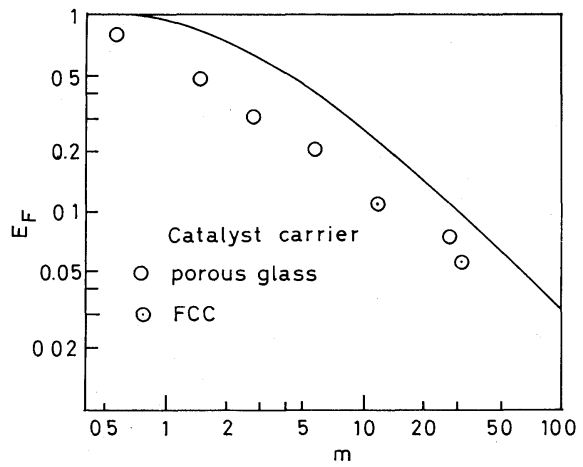

Fig. 14 Theoretical and experimental effectiveness factor

sity factors were used to estimate the effective diffusion coefficient of ethylene at the reaction temperature $\left(70^{\circ} \mathrm{C}\right)$.

According to Glasstone et al. ${ }^{4)}$, activation energy for the viscous flow of water (temperature dependency of viscosity) is $-5.06\left(0^{\circ} \mathrm{C}\right),-3.42\left(50^{\circ} \mathrm{C}\right)$ and $-2.8\left(100^{\circ} \mathrm{C}\right)$ in $\mathrm{kcal} / \mathrm{mol}$ and it is equivalent to that for diffusion, though the sign is reversed. The observed activation energy for the porous glass in the range of 5 to $35^{\circ} \mathrm{C}, 4.9 \mathrm{kcal} / \mathrm{mol}$, (Fig. 13) agrees well with that of the viscous flow at $0^{\circ} \mathrm{C},-5.06 \mathrm{kcal} / \mathrm{mol}$. Based on this fact, the molecular diffusion coefficient of ethylene at $70^{\circ} \mathrm{C}$ was estimated from the available literature value at $25^{\circ} \mathrm{C}$, assuming the activation energy to be $3.42 \mathrm{kcal} / \mathrm{mol}$. The effective diffusivity was obtained from the molecular diffusivity and the tortuosity factor.

$$
\begin{aligned}
& D_{e}=6.56 \times 10^{-6} \mathrm{~cm}^{2} / \mathrm{sec} \text { (the porous glass) } \\
& D_{e}=3.18 \times 10^{-5} \mathrm{~cm}^{2} / \mathrm{sec} \text { (the porous alumina) }
\end{aligned}
$$

\section{Analyses}

The reaction has been proved to follow a first order rate law in respect to the concentration of ethylene, and the intrinsic rate constant and the effective diffusion coefficient have been experimentally obtained. Thiele modulus, therefore, can be determined for each size of catalyst. Fig. 14 shows the experimental effectiveness factor $\left(=k_{\mathrm{obs}} / k_{\text {intrinsic }}\right)$ versus the modulus. The experimental results agree with the theoretical relation between the effectiveness factor and the modulus. The effectiveness factors for the different carrier materials coincide with each other, since the difference of their effective diffusion coefficients was taken into account.

The apparent difference of the activation energy and the reaction rate dependency on $\left[\mathrm{Pd}^{2+}\right]$ in the supported liquid-phase catalyst from the intrinsic reaction could be attributed to the poor effectiveness factor of the catalyst. Under the condition where the kinetic studies were made, the effectiveness factor can be approximated by $3 / \mathrm{m}$. Therefore,

$$
r_{\mathrm{obs}}=k_{\mathrm{obs}}\left[\mathrm{C}_{2} \mathrm{H}_{4}\right]=k E_{f}\left[\mathrm{C}_{2} \mathrm{H}_{4}\right]=\frac{3 \sqrt{k D_{e}}}{R}\left[\mathrm{C}_{2} \mathrm{H}_{4}\right]
$$

From this relationship, the apparent activation energy for the supported liquid-phase catlayst is

$$
\left.E_{\text {obs }}=\left(E_{r}+E_{d}\right) / 2=9.1(\mathrm{kcal} / \mathrm{mol})\right)
$$

This prediction coincides with the calculated results of the experiments $(9.6 \mathrm{kcal} / \mathrm{mol})$.

The apparent dependency of the reaction rate constant on $\left[\mathrm{Pd}^{2+}\right]$ may be given by

$$
k_{\mathrm{obs}} \propto k^{1 / 2} \cdot \propto\left[\mathrm{Pd}^{2+}\right]^{0.83 / 2}
$$

The small discrepancy of this prediction compared with the experimental result $\left(\left[\mathrm{Pd}^{2+}\right]^{0.57}\right)$ may be reasonably explained by taking into account oozing of the catalyst solution by thermal expansion. When the catalyst pellets were put into the reactor at an elevated temperature, a very small amount of catalyst solution oozed from the pellets, possibly to yield small liquid drops at the contact points between the pellets. The reaction in the small liquid drops may not be ignored in the region of high concentrations of $\mathrm{Pd}^{2+}$, because the pellet effectiveness factor is very small.

Thus, it is demonstrated that the behavior of the supported liquid-phase catalyst is characterized by the homogeneous reaction under the influence of intraparticle diffusion.

\section{Dispersion of the Catalyst Solution in Carrier Ma- terials}

While the effectiveness factor approaches unity at a pellet size as small as about $50 \mu$ in this catalyst system, this size is not practical for a fixed-bed reactor. It may be that such a problem often arises for this type of catalyst-holding system because of the small diffusivity in liquid. If the catalyst solution is dispersed in carrier materials as small fluid particles, the empty pores will permit rapid gas-phase diffusion and lead to a high effectiveness factor.

A centrifugal separator may be suitably used to make such a catalyst structure. In the field of centrifugal force, a catalyst solution is held by surface tension. If a cylindrical pore (radius $r_{p}$ and length 1 ) is located perpendicularly to the centrifugal force, the force balance equation is expressed as 


$$
2 \pi r_{p} \sigma \cos \theta^{\circ}=\pi r_{p}^{2} l \rho L(2 \pi n)^{2}
$$

where $\sigma$ and $\rho$ are, respectively, the interface tension and the density of the solution, $\theta^{\circ}$ is the contact angle between the solution and the interior wall of the pore, $L$ is the length of the arm of the centrifugal separator, and $n$ is the number of revolutions. Eq. (10) leads to

$$
r_{\text {eritical }}=\frac{\sigma \cos \theta^{\circ}}{2 \pi^{2} \rho L n^{2} l}
$$

Equation (11) shows that the solution in the pores of the radius smaller than $r_{\text {critical }}$ won't be removed at all, but that some portion of the solution in larger pores will be removed. This treatment is an approximation for the complex structure of pores. Eq. (11), however, can give information on the coarseness of pores of the carrier materials to be used, by means of a centrifugal separator, for obtaining a highly dispersed state of catalyst solution. To get the approximate value of $r_{\text {critical }}$, each value was substituted into Eq. (11), assuming that the pore length is equal to the diameter of the pellet $(1.0 \mathrm{~cm})$ and that $n$ is $1000 \mathrm{rpm}$. Then

$$
r_{\text {critical }}=6.4 \mu
$$

This value indicates that the pore size of the alumina used in this study is appropriate for the purpose stated above.

The porous alumina of $1.0 \mathrm{~cm}$ (diameter) supporting the liquid-phase catalyst was treated by a centrifugal separator. Using the resultant catalyst pellets, measurements were made to examine the content of the liquid-phase catalyst and their catalytic activity.

Fig. 15 shows the relation between the fraction of the catalyst solution in the whole pore volume $(\varepsilon)$ and the duration of the centrifugal operation, at different speeds of the centrifugal separator. The fraction of the catalyst solution became almost constant within a minute, by a rapid equilibration.

In the theoretical treatment shown above, an assembly of cylindrical pores was assumed. More realistically, the pore is considered to be structured as the void of a large number of fine particles. The catalyst solution would be held in dispersed form at the interstices in the vicinity of the contact points of the fine particles. Such a structure would be exactly what was intended beforehand. The results of the reaction rate measurements are shown in Fig. 16, in which the effectiveness factor is defined as the actual activity relative to the potential activity of the catalyst solution. The effectiveness factor increases with decreasing content of the catalyst solution and becomes unity at $\varepsilon=0.4$, indicating that the effective size of the liquid particles dispersed in the pellet becomes smaller than $50 \mu$. In Fig. 16, the pellet activity relative to the case where the whole pore volume is filled with

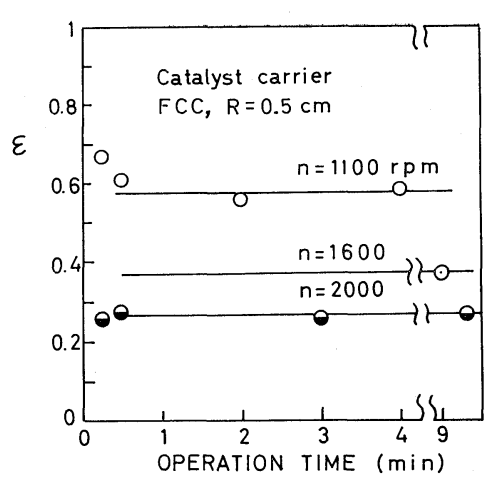

Fig. 15 Content of catalyst solution after centrifugal operation

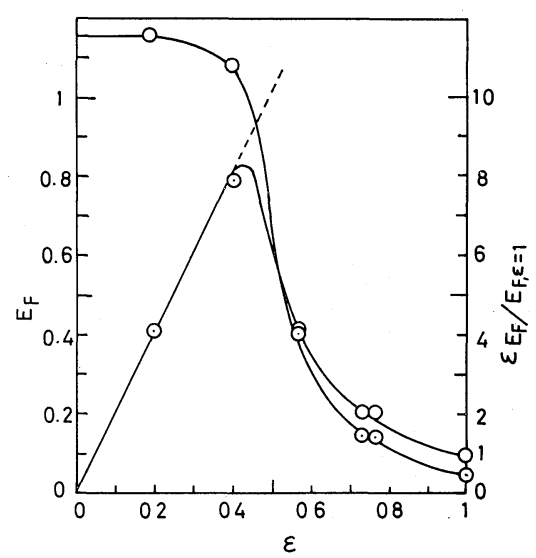

Fig. 16 Catalyst activity vs. content of catalyst solution

the catalyst solution $\left(\varepsilon E_{f} / E_{f, \varepsilon=1.0}\right)$ is also shown. The pellet activity increases with decreasing content and becomes eight times $\varepsilon=1.0$ at $\varepsilon=0.4$. At the lower content the pellet activity decreases proportionally to the content, since the catalyst solution functions under reaction control.

Thus, a technique to raise pellet activity without reducing the size, and to operate a reaction at any assigned effectiveness factor has been successfully established. For this purpose, the carrier material must be of a proper pore structure. Catalyst solution supported by porous glass was not removed even under a very large centrifugal force, because of the small pore diameters. Furthermore, using a porous material of a too rough pore structure resulted in the flowing out of the catalyst solution because of gravity.

\section{Conclusion}

This paper is concerned with liquid-phase catalyst supported by a porous material, a stationary bed of which eliminates various difficulties encountered in the ordinary industrial equipment for gas-liquid catalytic reactions of the gas-bubbling type.

The stable operation observed in the experiments for the Wacker-Höchst process proved clearly the applicability of the catalyst system to this process, 
despite the high vapor pressure of the catalyst solution. The behavior of the catalyst was predicted by applying the theory of reaction and diffusion in porous media.

The difficulty posed for this type of catalyst was its low activity in the ordinary-sized carrier material resulting from significant diffusion resistance in liquid. A centrifugal separator was proved to be a powerful means to the solution of the porblem. When a centrifugal force is added to the catalyst, the catalyst solution in the larger pores is removed but in the smaller pores it still remains and the resultant catalyst structure allows rapid diffusion through the empty pores. The activity and the effectiveness factor of the catalyst pellet is easily controlled by the speed of the separator, through the content of the catalyst solution in the whole pore volume.

\section{Nomenclature}

[A] $=$ concentration of A component $\quad[\mathrm{mol} / \mathrm{l}]$

C $=$ concentration of $\mathrm{KCl} ; C_{\infty}$ is concentration after infinite time $[\mathrm{mol} / l]$

$D_{e} \quad=$ effective diffusivity $\quad\left[\mathrm{cm}^{2} / \mathrm{sec}\right]$

$E_{d} \quad=$ activation energy for diffusion; $E_{r}$ is activation energy for reaction and $E_{\mathrm{obs}}$ is observed activation energy [ $\quad[\mathrm{kcal} / \mathrm{mol}]$

$E_{f} \quad=$ catalyst effectiveness factor $\quad[-]$

$F \quad=$ volumetric flow rate in a reactor; $F^{\circ}$ is flow rate at room temperature $[1 / \mathrm{sec}]$

$K=$ gas-liquid partition coefficient for ethylene (Eq. 8) [-]

$k=$ reaction rate constant defined by Eq. (6) $\left[\mathrm{sec}^{-1}\right]$

$k^{\circ} \quad=$ reaction rate constant in the rate form of $r=k^{\circ}\left[\mathrm{Pd}^{2+}\right]\left[\mathrm{C}_{2} \mathrm{H}_{4}\right] /\left[\mathrm{H}^{+}\right]\left[\mathrm{Cl}^{-}\right]^{2} \quad\left[\mathrm{~mol}^{2} / l^{2} / \mathrm{sec}\right]$

$L=$ arm length of centrifugal separator $\quad[\mathrm{cm}]$

$l \quad=$ length of cylindrical pore $\quad[\mathrm{cm}]$

$m \quad=$ Thiele modulus [-]

$n \quad=$ number of revolutions [rps]

$p \quad=$ partial pressure $\quad[\mathrm{atm}]$
$R \quad=$ radius of catalyst carrier $\quad[\mathrm{cm}]$

$r \quad=$ reaction rate

[mol-ethylene/ $l$-catalyst solution/sec]

$r_{p} \quad=$ radius of cylindrical pore; $r_{\text {critical }}$ is radius given by Eq. (11) [cm]

$\begin{array}{lll}T & =\text { temperature } \quad\left[{ }^{\circ} \mathrm{C}\right]\end{array}$

$W \quad=$ total volume of catalyst solution in a reactor

$\varepsilon \quad=$ fraction of pore volume occupied by catalyst solution

$\theta \quad=$ porosity

$\theta^{\circ} \quad=$ contact angle

$\rho \quad=$ density of liquid

$=$ density of liquid
$=$ interface tension

\section{Literature Cited}

1) Acres, G. J. K., G. C. Bond, B. J. Cooper and J. A. Dawson: J. of Catalysis, 6, 139 (1966).

2) Crank, J.: "Mathematics of Diffusion", p. 90, Oxford at the Clarendon Press (1956).

3) Dozono, T. and T. Shiba: Bull. Japan Petrol. Inst., 5, 8 (1963).

4) Glasstone, S., K. J. Laidler and H. Eyring: "The Theory of Rate Processes", p. 505, McGraw Hill (1941).

5) Henry, P.: J. Am. Chem. Soc., 86, 3246 (1964).

6) Komiyama, H. and H. Inoue: J. Chem. Eng. Japan, 1, 142 (1968).

7) ibid, 3, 206 (1970).

8) Mitsutani, A. and K. Tanaka: Shokubai (Catalyst, Japan), 4, 388 (1962).

9) Moraves, R. Z., W. T. Schelling and C. F. Oldershaw: Brit. Patent, 511, 566 (1939).

10) idem: Can. Patent, 396, 994 (1941).

11) Rony, P. R.: Chem. Eng. Sci.: 23, 1021 (1968).

12) idem: J. of Catalysis, 14, 142 (1969).

13) Schmidt, J., W. Hafner, R. Jira, J. Seldmeier, R. Sieber, R. Ruttinger and H. Køjer: Angew. Chem., 71, 176 (1959).

14) Stern, E. W.: "Catalysis Review" vol. 1, p. 73, Marcel Dekker (1968).

15) Vargaftik, M. N., J. I. Moiseev and Ya. K. Sirkin: Dokl. Akad. Nauk SSSR, 147, 399 (1962). 